\title{
Niobium Pentoxide thin films employ simple colloidal suspension at low preparation temperature
}

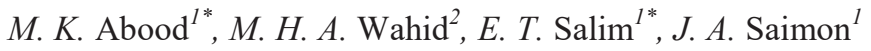 \\ ${ }^{1}$ Laser Science Branch, University of Technology, 10066 Baghdad, Iraq \\ ${ }^{2}$ Semiconductor Photonics \& Integrated Lightwave Systems (SPILS), School of Microelectronic Engineering, University \\ Malaysia Perlis, Pauh Putra Campus, Arau 02600 Malaysia
}

\begin{abstract}
In this work a nano-colloidal suspension is used to prepare $\mathrm{Nb}_{2} \mathrm{O}_{5}$ thin films. The effect of different substrates on structural properties of niobium pentoxide thin film deposited by spin coating technique on silicon and quartz substrates are presented. We observed that the obtained structure is monocline in both substrates. The diffraction peaks in both substrates ensured the successful formation of $\mathrm{Nb}_{2} \mathrm{O}_{5}$ thin films with a clear polymorphous structure. However, the structure became more crystalline with additional distinguished peaks on silicon substrate comparing to quartz substrate. The extracted structural parameters from X- Ray diffraction show that the grain size of the thin films on quartz is smaller than silicon with the values of $16.47 \mathrm{~nm}$ and $20.98 \mathrm{~nm}$ respectively. The stress measurement records the values of 0.19 and 0.00719 for the thin films deposited on silicon and quartz substrates respectively. Effects of film thickness depicted increment in the absorbance and reduction in the band gap. Energy gaps of 2.7, 2.58 and, $2.5 \mathrm{eV}$ are measured as a result of increasing the film thicknesses of 325,420 and $450 \mathrm{~nm}$ respectively.
\end{abstract}

\section{Introduction}

Niobium pentoxide $\left(\mathrm{Nb}_{2} \mathrm{O}_{5}\right)$ is an n-type semiconductor with a broad band gap of 2.8-3.4 eV [1, 2]. It has abundant polymorphic shapes which give height to a pleasant series of structural phases [3] that rely on composition mechanisms, pressure and temperature. Thus, it enables existent various physical characteristics like a semiconductor or as a dielectric material, relying on the similarity. The phases are mostly established on $\mathrm{NbO}_{6}$ octahedral groups, shaping different arrangements from the rectangular blocks or columns [4-9]. It is supposed that numerous of the present phases must be metastable or, fully, stabilized through impurities [5]. An appropriate incorporation of chemical, electronic and optical characteristic produces this oxide which helpful in different applications [6-9].

From the technological viewpoint, the $\mathrm{Nb}_{2} \mathrm{O}_{5}$ is significantly noted on account of its energy absorption existence in the ultraviolet region. Hence, this possibly be utilized to safeguard materials from that irradiation [10-12]. In addition, $\mathrm{Nb}_{2} \mathrm{O}_{5}$ films have been exploited greatly as optical interference filters, solar cell, gas sensors materials, electrochromic devices [13-16], and etc.

Different physical or chemical growing procedures have been advanced to present $\mathrm{Nb}_{2} \mathrm{O}_{5}$ thin films and nanostructures such as pulsed laser deposition, reactive RF magnetron sputtering, atomic layer deposition, and sol-gel [17-20].

\section{Methodology}

The required niobium pentoxide colloidal solution was obtained using $\mathrm{Nb}_{2} \mathrm{O}_{5}$ powder (ultra-purity, 99.99\%); hydrofluoric acid and ammonia without further purification. The chemicals were prepared with the following molar ratio 1:1:4:8 of DIW, ethanol, HF, and $\mathrm{Nh}_{3} \mathrm{OH}$ respectively, and added with $0.2 \mathrm{~g} \mathrm{Nb}_{2} \mathrm{O}_{5}$ powder. Firstly, the hydrofluoric acid and $\mathrm{Nb}_{2} \mathrm{O}_{5}$ were mixed together with continuous heating and stirring for 1 hour until a transparent solution was obtained. After that ammonia, water and ethanol were added with constant stirring for 1 hour in water bath at $100^{\circ} \mathrm{C}$. A milky like colloidal solution was observed at this stage. The chemical reactions can be simplified as follows [21,22].

$$
\begin{gathered}
\mathrm{Nb}_{2} \mathrm{O}_{5}+10 \mathrm{HF} \rightarrow 2 \mathrm{H}_{2}\left[\mathrm{NbOF}_{5}\right]+3 \mathrm{H}_{2} \mathrm{O} \\
2 \mathrm{H}_{2}\left[\mathrm{NbOF}_{5}\right]+10 \mathrm{NH}_{4} \mathrm{OH} \rightarrow \mathrm{Nb}_{2} \mathrm{O}_{5} \downarrow+10 \mathrm{NH} 4 \mathrm{~F}+7 \mathrm{H}_{2} \mathrm{O}
\end{gathered}
$$

A spin coating technique was employed to achieve homogeneous $\mathrm{Nb}_{2} \mathrm{O}_{5}$ thin films. The colloidal solution was deposited on quartz and silicon substrates at a

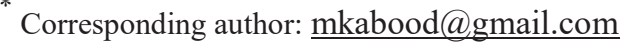


spinning speed of $2500 \mathrm{rpm}$ in $1 \mathrm{~min}$. Its structural property is recorded by using x-ray diffraction technique (Shimadzu6000). Later, three different thicknesses $\mathrm{T}_{1}=325, \mathrm{~T}_{2}=420$ and $\mathrm{T}_{3}=450 \mathrm{~nm}$ were deposited on quartz substrate for the study of optical properties by uvvisible spectrophotometer (T60 UV-Vis). Morphological characterization was performed using scanning electron microscope (AA-3000).

In this work, preparation and characterization of niobium pentoxide thin films at low temperature without post heat treatment using new raw material is established. It is the first of its kind in film's fabrication in our knowledge. The effect of the substrate types on structural properties of the $\mathrm{Nb}_{2} \mathrm{O}_{5}$ deposited thin film was also investigated.

\section{Results and discussion}

\subsection{Structural studies}

The crystal structure and orientation of the $\mathrm{Nb}_{2} \mathrm{O}_{5}$ films was inspected by XRD patterns. Figure 1 shows the XRD output of the prepared sample from deposition of the chemical colloidal suspension without ammonia.

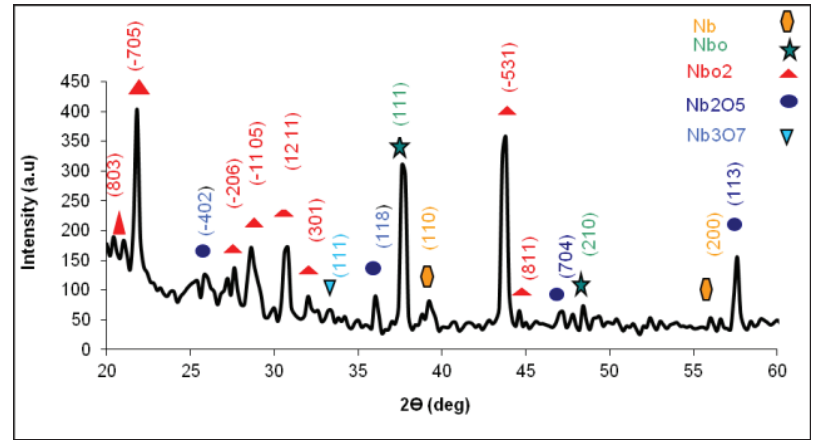

Fig. 1. X-ray diffraction spectrum for the prepared thin films before adding ammonia

The diffraction peaks indicate amorphous structure. It is also proved the existence of niobium metal in addition to different niobium oxidation degree at different phases $\mathrm{Nb}, \mathrm{NbO}, \mathrm{NbO}_{2}, \mathrm{Nb}_{2} \mathrm{O}_{5}$ and $\mathrm{Nb}_{3} \mathrm{O}_{7}$. However, niobium monoxide $\mathrm{NbO}$ is the dominated one. The main diffraction peaks belong to different niobium oxide phases are located at 21.80, 28.60, 30.80, 37.80, 43.80 and 57.60 which identify the (-705), (-11 05), (12 $11),(111),(-531)$ and (113) respectively.

When the ammonia was added the structure totally changed as shown in Figure 2. All the diffraction peaks of the $\mathrm{Nb}_{2} \mathrm{O}_{5}$ films deposited on quartz substrate were corresponded to the peaks of standard Card (00-0371468). While the diffraction peaks of the thin film deposited on silicon substrate matched to the standard Card (00-030-0872). The diffraction peaks in both cases ensured the successful formation of $\mathrm{Nb}_{2} \mathrm{O}_{5}$ thin films with a clear polymorphous structure, but the structure became more crystalline with more distinguished peaks when deposited on silicon substrate comparing with quartz substrate.
The dominated diffraction peaks for quartz and silicon substrates were referred to (301) and (111) diffraction plane respectively, which insure the formation of monoclinic crystalline structure in both cases. The impurities $(\mathrm{NbO})$ were present in the two substrates represented by (011) and (101) diffraction planes for quartz and silicon respectively. However, its intensity was monitored to be smaller in silicon substrate.

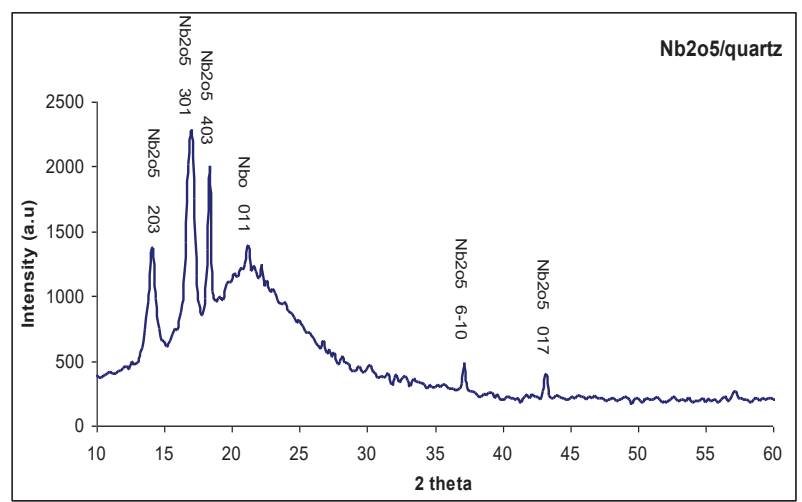

(a)

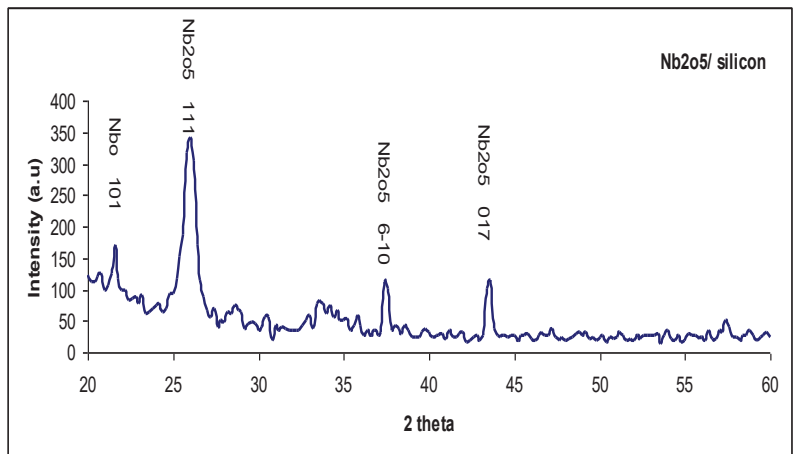

(b)

Fig. 2. X-ray diffraction spectrum for the prepared thin films deposited on (a) quartz and (b) silicon substrates

The parameters which discerned the structure of deposited thin film on silicon and quartz were characterized base on the analysis of XRD results and calculated using the values summarized in Table 1. In addition, the following equations were applied in the analyses:

$$
\begin{gathered}
D=\frac{K \lambda}{\beta \cos \theta} \\
\delta=\frac{1}{D^{2}} \\
\varepsilon=\frac{\beta}{4 \tan \theta}
\end{gathered}
$$

where D is grain size in (nm), K is constant depended on the used X-Ray wave length, $\beta$ is the full width at half maximum, $\Theta$ is the diffracted angle, $\delta$ is the density of dislocation which refers to the number of dislocations in a unit volume of a crystalline material and $\varepsilon$ is the stress [23-30]. 
The structural parameters in Table 1 indicate that the thin film deposited on quartz substrate has grain size smaller than silicon substrate. Furthermore, the density of dislocations or deformations is larger in quartz substrate about $4.1 \times 10^{-3}$ compare to $2.51 \times 10^{-3}$ for silicon substrate. Besides, the average value of stress is smaller for quartz substrate than silicon with values of 0.00719 and 0.19 respectively. This is attributed to the existence of preferred growth orientation in the silicon substrate [31].

Table 1. Structural parameters extracted from X-ray diffraction method

\begin{tabular}{|c|c|c|c|c|c|c|}
\hline & $\begin{array}{c}2 \Theta \\
(\mathrm{deg})\end{array}$ & $\begin{array}{c}\mathrm{d} \\
\text { spacing } \\
\left(\mathrm{A}^{\circ}\right)\end{array}$ & hkl & $\begin{array}{r}\text { D } \\
\text { nm) }\end{array}$ & $\begin{array}{r}\delta \\
* 10^{-3} \\
\quad(1 \\
\text { ine/m } \\
\left.{ }^{2}\right)\end{array}$ & $\varepsilon$ \\
\hline \multirow{4}{*}{ : } & 21.20 & 4.10 & 101 & 26.42 & 1.43 & 0.21 \\
\hline & 26.00 & 3.4 & 111 & 16.08 & 3.87 & 0.28 \\
\hline & 37.40 & 2.39 & 601 & 19.06 & 2.75 & 0.15 \\
\hline & 43.60 & 2.07 & 017 & 22.36 & 2.00 & 0.11 \\
\hline 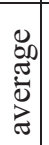 & & & & 20.98 & 2.51 & 0.19 \\
\hline \multirow{5}{*}{ 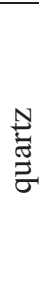 } & 14.2 & 6.2 & 203 & 13.9 & 5.1 & 0.0057 \\
\hline & 17.0 & 5.2 & 301 & 12.0 & 7.0 & 0.0109 \\
\hline & 18.4 & 4.8 & 403 & 21.0 & 2.3 & 0.0052 \\
\hline & 37.2 & 2.4 & 610 & 17.18 & 3.3 & 0.0074 \\
\hline & 43.2 & 2.0 & 017 & 18.23 & 3.0 & 0.0067 \\
\hline 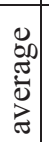 & & & & 16.47 & 4.1 & 0.00719 \\
\hline
\end{tabular}

\subsection{Optical studies}

Optical properties of the deposited thin film on quartz substrate were observed using uv-visble spectrophotometer as shown in Figure 3.

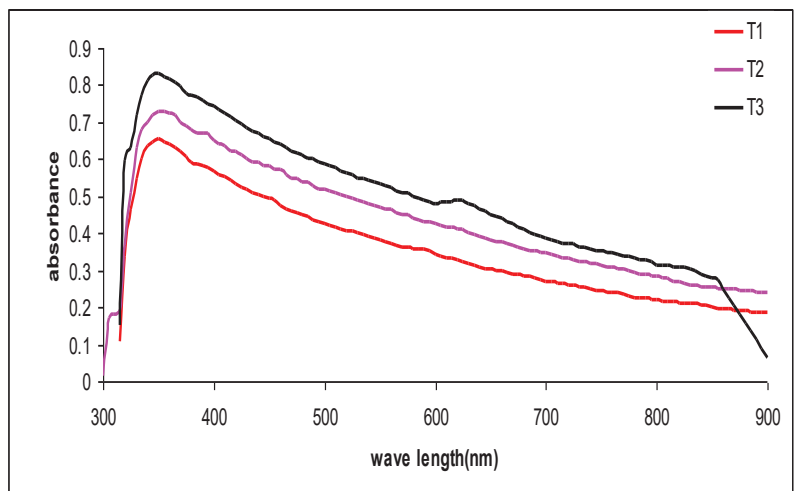

Fig. 3. Relation between the wave length and the absorbance of the prepared thin films deposited on quartz substrate with three different thicknesses
It is clearly depicted that the absorbance intensity of the deposited thin films increases with the thickness. This is due to the increment density of $\mathrm{Nb}_{2} \mathrm{O}_{5}$ particles which absorbed the photons, hence the absorbance increases. It was similarly recorded in Ref. [33] that gave good agreement with our observation.

Energy gap estimation using absorption spectrum of the deposited thin films with different thicknesses is shown in Figure 4. It indicates that the energy gap decreases with thickness from 2.7, 2.58 and $2.5 \mathrm{eV}$ to $\mathrm{T}_{1}$, $\mathrm{T}_{2}$ and $\mathrm{T}_{3}$ respectively. This is due to the improvement in the crystals, changes in the morphology of the deposited films, atomic distances variation and the existence of structural defects in the films [32].

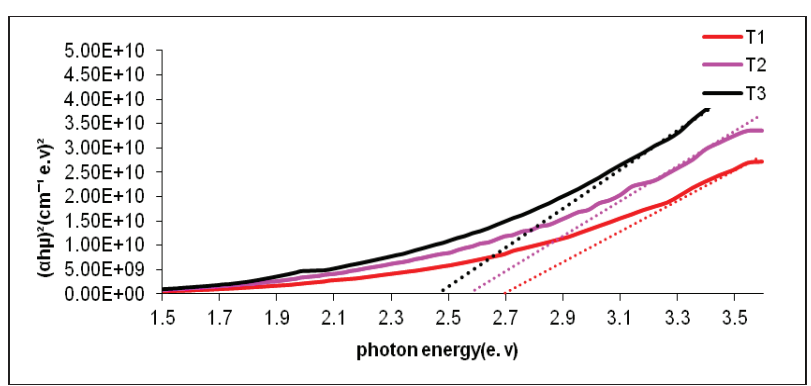

Fig. 4. Energy gap estimation for $\mathrm{Nb}_{2} \mathrm{O}_{5}$ thin films deposited on quartz substrate with three different thicknesses

\subsection{Morphological studies}

The morphological properties for $\mathrm{Nb}_{2} \mathrm{O}_{5}$ thin film deposited on quartz substrate are shown in SEM micrograph in Figure 5. The formation of microstructure with an earth rock like structure along the films surface is visibly noted. Such structure is a normal characteristic of films derived from sol-gel method [34].

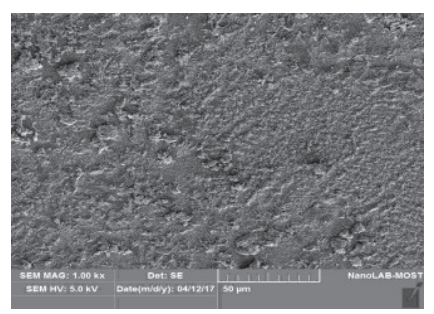

(a)

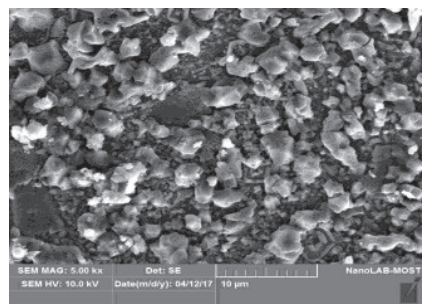

(b)

Fig. 5. Scanning electron microscope micrograph for thin film deposited on quartz substrate (a) $50 \mathrm{um}$ scale and (b) $10 \mathrm{um}$ scale 


\section{Conclusion}

$\mathrm{Nb}_{2} \mathrm{O}_{5}$ thin films were successfully prepared using niobic acid based colloidal solution as a raw material at room temperature. The films were fabricated on quartz and silicon substrates using spin coating method. Structural parameters extracted from X- Ray diffraction showed many niobium oxide phases resulting from the complete dissolved of the raw material in the chemical reaction. A clear formation of $\mathrm{Nb}_{2} \mathrm{O}_{5}$ thin films was observed at a certain amount of ammonia. The thin films deposited on quartz have smaller grain size and stress but they have higher density of dislocation. Optical properties revealed an increase in the absorbance and a decrease in the band gap as a result of film thickness increment.

\section{References}

1. H. Luo, W. Song, P. G. Hoertz, K. Hanson, R. Ghosh, S. Rangan, M. K. Brennaman, J. J. Concepcion, R. A. Binstead, R. A. Bartynski, R. Lopez, T. J. Meyer Chem. Mater. 25, 122, (2013).

2. Y. Zhou, Z. Qiu, M. Lu, A. Zhang, and Q. Ma Journal of Luminescence 128, 1369, (2008).

3. G. C. Vezzoli, Phys. Rev. B 26, 3954, (1982).

4. H. Sch“afer, R. Gruehn and F. Schulte, Angew. Chem., Int. Ed. Engl. 5, 40-52, (1966).

5. S. Tamura, J. Mater. Sci. 7, 298-302, (1972).

6. J. Z. Ou, R. A. Rani, M. H. Ham, M. R. Field, Y. Zhang, H. Zheng, P. Reece, S. Zhuiykov, S. Sriram, M. Bhaskaran, et al., ACS Nano 5, 4045-4053, (2012).

7. X. Fang, L. Hu, K. Huo, B. Gao, L. Zhao, M. Liao, P. K. Chu, Y. Bando, D. Golberg, Adv. Funct. Mater. 21, 3907-3915, (2011).

8. S. Qi, R. Zuo, Y. Liu, Y. Wang, Mater. Res. Bull. 48, 1213-1217, (2013).

9. C. Nico, T. Monteiro, M. P. F. Gracca, Prog. Mater. Sci. 80, 1-37, (2016).

10. A. G. S. Prado, L. B. Bolzon, C. P. Pedroso, A. O. Moura, L. L. Costa Appl. Catal., B 82, 219, (2008).

11. A. M. Ferrari-Lima, R. G. Marques, M. L. Gimenes, N. R. C. Fernandes-Machado Catal. Today 254, 119, (2015).

12.H. A. J. L. Mourão, V. R. Mendonça, A. R. Malagutti, C. Ribeiro Quim. Nova 32, 2181, (2009).

13. I. Sieber, H. Hilderbrand, A. Friedrich, P. Schmuki, Electrochem. Commun. 7, 97, (2005).

14. P. Viswanathamurthi, N. Bhattarai, H.Y. Kim, D.R. Lee, S.R. Kim,M.A. Morris, Chem. Phys. Lett. 374, 79, (2003).

15. R. Ghosh, M.K. Brennaman, T. Uher, M.R. Ok, E.T. Samulski, L.E. McNeil et al., ACS Appl Mater Interfaces 3, 3929-3935, (2011).

16. M. Schmitt, S. Heusing, M.A. Aegerter, A. Pawlicka, C. Avellaneda, Sol. Energy Mater. Sol. Cells 54, 9, (1998).
17. Z. Weibin, W. Weidong, W. Xueming, C. Xinlu, Y. Dawei, S. Changle, P. Liping, W. Yuying and B. Li Surf. Interface Anal. 45, 1206-1210, (2013).

18. O. D. Coskun and S. Demirela Appl. Surf. Sci. 277, 35-39, (2013).

19. T. Blanquart, J. Niinisto, M. Heikkila, T. Sajavaara, K. Kukli, E. Puukilainen, C. Xu, W. Hunks, M. Ritala and M. Leskela Chem. Mater. 24, 975-980, (2012).

20. M. R. Joya, J. J. B. Ortega, A. M. R. Paez, J. G. da S. Filho and P. de T. C. Freire, Metals 7, 142, (2017).

21. O S Ayanda and F A Adekola, Journal of Minerals \& Materials Characterization \& Engineering 10, 245, (2011).

22. N Izabela and Z Maria Chemical Reviews 99, 3603, (1999).

23. E.T. Salim, M.A. Fakhri, H. Hasan, Int. J. Nanoelectronics and Materials 6, 121-128, (2013).

24. Zaid T Salim, U Hashim, MK Md Arshad, Makram A Fakhri, Materials Research Bulletin 86, 215-219, (2017).

25. M. A. Fakhri, U. Hashim, E. T. Salim, Z. T. Salim, Journal of Materials Science: Materials in Electronics 27 (12), 13105-13112, (2016).

26. E. T Salim, M. S Al Wazny, M.A Fakhry, Modern Physics Letters B, 27, (2013).

27. Fakhri, M.A., et al., Applied Physics B, 121(1), p. 107-116, (2015).

28. E.T.Salim, Indian Journal of Physics 87, 349, (2013).

29. M. A. Muhsien, $\quad$ E. T. Salem, I. R. Agool, H. H. Hamdan, Applied Nanoscience 4 (6), 719-732, (2014).

30. A. Kadhim, E. T. Salim, S. M. Fayadh,A. A. AlAmiery, A. Amir H. Kadhum, and A. B. Mohamad, The Scientific World Journal, (2014).

31.Fan, L. and R. Muller, Solid-State Sensor and Actuator Workshop, Technical Digest, (1988).

32. M. A. Fakhri, Y. Al-Douri, U. Hashim, E. T. Salim, Advanced Materials Research 1133, 457-461, (2016).

33. Akaltun, Y., et al., Optics Communications, 284(9), p. 2307-2311, (2011).

34. W-K Kim and et al. Optics Express 17, 2638, (2009). 